\title{
SCOLIOSIS AND SPORT
}

\author{
Slavica $\boxplus$. Jandrić ${ }^{1}$ \\ ${ }^{1}$ School of medicine, University of Banja Luka, Bosnia and Hrezegovina
}

EDITORIAL ARTICLE OWERVIEV PAPER UDC: $616.711: 796$

\section{SUMMARY}

In the course of growth and development, affected by various internal and external factors, various postural disorders may occur, especially in school-age children. Scoliosis is defined as a lateral curvature of the spinal column in the coronal plane, but the disorder actually occurs in three dimensions. The prevalence of scoliosis is from $2 \%$ to $3 \%$, and it is the highest in patients in the 12-14 age range, affecting girls more than boys at a ratio of 2:1. Functional scoliosis occurs more frequently than structural scoliosis. Idiopathic scoliosis is structural scoliosis which has no definite cause; it may progress and affect the function of internal organ systems and occurrence of back pain. Annual children's medical check-ups and early detection of scoliosis are essential for treatment of scoliosis. Treatment depends on the size and progression of the curve, skeletal maturity, scope of physical therapy and observation. The potential association between adolescent idiopathic scoliosis and sports is still insufficiently researched. Young athletes may have spinal deformities which are not related to any sports activity or may be potentially associated with the sport they practise. The International Scientific Society on Scoliosis Orthopaedic and Rehabilitation Treatment has come up with the guidelines for sports activities in children with scoliosis. This association does not recommend sport for treatment of idiopathic scoliosis. Sports activities are recommended due to their specific useful effects in the psychological, neuromuscular and general aspect of health in patients with scoliosis, even in patients during the treatment with spinal orthoses. In patients with a high risk of scoliosis progression, it is recommended to avoid competitive activities with a higher degree of mobility of the spinal column.

Key Words: posture, prevention, scoliosis, sport, treatment.

\section{INTRODUCTION}

In the course of growth and development in childhood, and later as well, various postural disorders may occur, especially in school-age children. These disorders are affected by various internal and external factors. The modern way of life is one of the factors that reduce physical activity of children, which may have repercussions on the locomotor system. On the other hand, different sports may have both positive and negative implications on the musculoskeletal system and cause various postural disorders.

Posture. The term posture refers to position of the body as a whole, with all its domains, and with an important role of psychological, kinesiological, biomechanical and physiological implications. This complexity has provoked lack of consensus and much disagreement about the definition, diagnosis, means and methods of treating various postural disorders.

In anatomical terms, posture depends on the interaction of skeletal, muscular and noncontractile connective structures (including fascia, tendons and ligaments). The principles of normal posture include optimal loading of the skeletal system, balance between antagonistic muscle groups and optimal activity of internal organs. In postural disorders, there is an imbalance in the loads imposed on different areas. As long as the loading is within physiological limits, the changes are considered reversible. When the loading exceeds normal physiological limits over prolonged periods of time, structural changes occur in the skeletal bones, and impairment of this type is irreversible 
(Górecki et al., 2009; Labaziewicz, 2008). Long-term postural disorders may impair the normal functioning of internal body systems and cause back pain.

The spinal column makes the axis of the body and supports the whole skeleton. Vertebral bodies are bound together by the fibrocartilaginous discs and two longitudinal ligaments - anterior and posterior. Ligg. flava, thick and strong ligaments connecting the arches of two adjacent vertebrae are of great importance during spinal column extension and unburdening back muscles. Physiological curves of the spinal column give it a double " $\mathrm{S}$ " shape in the sagittal plane. They depend on the position of pelvis and sacrum in the body, and their distinctiveness is related to gender as well. In adults, the spinal column is slightly curved in a lateral direction to the right side, particularly in the thoracic region, therefore we talk about thoracic dextroscoliosis, which occurs due to incomplete symmetry of the body and more developed right hand (or left hand in left-handers).

The spinal column ensures the upright position, as well as motion of head, neck and trunk. At the same time, it serves as the base of numerous strong muscles of shoulder and pelvic girdle, which are important, apart from maintaining the upright position and good posture, for motion of upper and lower extremities. The whole spine behaves as a single joint. Moves are made around three main axes: anteflexion and retroflexion around the frontal axis, lateroflexion around the sagittal axis, and rotation around the vertical axis. The range of motion differs in separate parts of the spinal column.

The body constantly resists the force of gravity, and, in mechanical sense, maintains balance of forces. The active force which the organism uses to maintain the physical position in space is muscles. The spinal column is affected by the muscles which ensure the upright position of the body and take part in movement. The primary function of muscles includes support, stabilisation and mobility of the spinal column. In studying spinal deformities, particularly important is the role of deep muscles of the back and posterior cervical muscles (extensor muscles of the spinal column), m. quadratus lumborum (spine lateral flexor) and m. psoas major (thigh and spinal column flexor). The abdominal muscles bend and rotate the spine. The antagonistic activity of abdominal and back muscles ensures the upright position of trunk and its balance during walking. The superficial group of broad muscles serves for motion of upper extremities and ribs (m. trapesius, m. latissimus dorsi, m. levator scapulae, $m$. rhomboideus). The group of deep muscles of the back consists of eight muscles (m. splenii capitis et cervicis, m. erector spinae, m. spinalis, $\mathrm{m}$. transversospinalis, $\mathrm{mm}$. interspinales, $\mathrm{mm}$. intertransversarii and mm. coccygei). Deep muscles of the back fasten the spine to the bony pelvic ring like a strong elastic ribbon. The erector spinae tension is important for every move of trunk and head, for every step and change of the body position. When the spine bends sideways, $m$. iliocostalis and m. quadratus lumborum have a stronger effect. M. iliopsoas is the main flexor of the thigh towards the pelvis in the hip region.

\section{Postural disorders and scoliosis}

The most common postural disorders are postural disorders of the spinal column (scoliosis, kyphosis, lordosis) and postural disorders of lower extremities. The results of a research on the identification of prevalence and the main risk factors of bad posture in school-age children in the Czech Republic revealed that $38.3 \%$ of the children were diagnosed with bad posture, more frequently in the boys. The children with bad posture complained more frequently of a headache and pain in the region of cervical and lumbar segment of the spinal column. On the average, they participated in sports activities 4 hours a week, and they watched television and/or used computers and played computer games 14 hours a week. Twenty percent of the children included in the research did not participate in any sports. The authors came to the conclusion that in the group of children who did not participate in any sports the probability of bad posture was much higher than in the children who participated in some sport (Kratenová, Zejglicová, Malý, \& Filipová, 2007). Sedrez, Da Rosa, Noll, Medeiros, and Candotti (2015) report that a lifestyle may be associated with postural disorders. In this research conducted in Brazil, the prevalence of postural disorders was $79.7 \%$, out of which $47.5 \%$ had changes in the coronal plane and 61\% in the sagittal plane. Significant association was revealed between the presence of scoliosis and participation in competitive sports, as well as with the sleep time longer than 10 hours.

Scoliosis is defined as a lateral curvature of the spinal column in the coronal plane, but the disorder actually occurs in three dimensions (3D): apart from a lateral curvature in the coronal plane, there is also rotation (motion around the longitudinal axis in the transverse plane) and torsion (twisting of a part of a vertebral body towards another one, and a change of profile in the sagittal plane). The level of scoliosis prevalence may vary significantly in relation to the definition which is applied and to the population 
observed. If scoliosis is defined as a curvature greater than $10^{\circ}$ of Cobb angle, the prevalence is $2-3 \%$, and when a lower Cobb angle is taken (e.g. $6^{\circ}$ and higher), significantly higher prevalence of scoliosis is registered - the level of 4.5\% (Rogala, Drummond, \& Gurr, 1978). The prevalence is higher in patients in the 12-14 age range, and it affects girls more than boys at a ratio of 2:1 (Stirling et al., 1996).

Scoliosis is classified in terms of aetiology, pattern of the skeletal structure of the spinal column, correction of curvature, localisation, angle of curvature, type, direction of curvature and age in which deformity is detected. In terms of origin, scoliosis may be of unknown (primary or idiopathic) or known origin (secondary). The University of Washington classifies scoliosis into non-structural (postural and compensatory), temporary structural (sciatic, hysterical and inflammatory) and structural scoliosis. Structural scoliosis may be congenital and acquired. The most common structural scoliosis is idiopathic (70-80\%). In terms of correctibility (flexibility), scoliosis may be divided into functional (flexible) and structural (rigid) scoliosis.

In functional scoliosis there are no structural changes on the skeleton system, it occurs more frequently, curves are not fixed, and it is characterised solely by a lateral curvature of spine without rotation of vertebrae and trunk asymmetry. It is easy to correct it passively, particularly in body suspension, by trunk anteflexion, voluntary contraction of spine extension muscles, standing position test or manually, and it has a better prognosis as well (Taft \& Francis, 2003). In a forward bend test, it does not reveal a rib hump. Habitual scoliosis is also in this group. The cause of its occurrence is multifactorial. The spinal column which is already insufficient is affected by negative external influences (bad habits, improper sitting, carrying a schoolbag etc.). It is important to control postural scoliosis and maintain a mobile state of the locomotor system, along with strengthening postural muscles and correction of posture until the process of growing up ends. In many cases, untreated functional scoliosis may progress to severe rigid diseases. Due to its frequency and correctibility, postural scoliosis is a genuine subject of interest and work of educators and teachers of physical culture and sport in schools (Jovović, 2008). Compensatory scoliosis is caused by a static disorder (leg length discrepancy, muscle spasm, congenital hip dislocation, pain related to spinal disc herniation) (Jandrić \& Antić, 2006).

Structural scoliosis is characterised by a change in the structure and morphology of vertebral body. It is changed and wedge-shaped, with the top directed towards the concavity of the curve. Spinous processes are directed towards the concavity, and transverse processes are directed dorsally towards the convexity. The changed shape of a vertebra leads to rotation, which becomes particularly visible if the change takes place in the thoracic spine. For that reason, the "rib hump" occurs during forward bending motion of the trunk.

Idiopathic scoliosis. Structural scoliosis of unknown origin is called idiopathic scoliosis [IS], and it is quite common. It may progress along with growing up, and sometimes it may spontaneously disappear. In terms of age at the time of occurrence of idiopathic scoliosis, it is classified into infantile, juvenile and adolescent idiopathic scoliosis [AIS]. Infantile idiopathic scoliosis ( $0-3$ years) is more common in boys and is mainly sinistro-convex, in $90 \%$ of cases, with rapid progression. Juvenile idiopathic scoliosis in children in the 4-10 age range occurs equally in boys and girls. The primary curve is located in the thoracic spine, and it is more frequently dextro-convex. The earlier it occurs, and the more cranially its primary curve is located, the worse prognosis it has. Children with juvenile idiopathic scoliosis have to be under frequent control of doctors. AIS occurs in children between age 10 and the time they are fully grown. It is more common in girls and it is dextro-convex. It is very progressive and it may deteriorate as much as $10^{\circ}$ a year. Adolescence is a period of rapid changes in the organism, with tumultuous hormonal changes and disproportion between bone length and muscle force. Affected by the action of mechanical forces, the spinal column is susceptible to occurrence of various disorders. In this scoliosis, the prognosis is better, because the possibility of its progression is reduced due to the period of stabilisation of the spinal column. The earlier the curve occurs, and the more cranial localisation is, the worse prognosis it has (Jandrić, 2012a).

In terms of shape and localisation, scoliotic curves are classified into: a) thoracic, b) thoracolumbar, c) lumbar, and d) double major curve.

Diagnosis. In scoliosis diagnostics, the methods used are clinical examination, $\mathrm{X}$-ray examination and stereophotogrammetry. Clinical examination observes the spinal column line, position of pelvis, hips, knees, neck and shoulders. Observed are also Lawrence angles and trunk looked at from the front and from the back.

Clinical examination includes basic assessment of posture and body shape (inspection, palpation, conduct of Adam's forward bending test, measuring leg length, measuring range of motion, measuring with a plumb 
line), cardiopulmonary status and neurological examination. Stereophotogrammetry determines deformity on the basis of display of symmetry of contours in the region of the back. Using radiography, we determine the degree of curvature, rotation of vertebral bodies and skeletal maturity of the patient.

Prevention and treatment. Examinations of children and sports medical examinations are essential for early detection and treatment of AIS. The American Academy of Orthopaedic Surgeons, Scoliosis Research Society, Pediatric Orthopaedic Society of North America and American Academy of Pediatrics recommend the optimal time for detection of AIS and conduct of screening as follows: two times for girls (10-12 age range) and once for boys (13 or 14 years of age) in 2008. During routine examinations of children and/or school medical examinations, scoliosis screening helps in identification of patients who need monitoring and therapy, while evaluation of the scoliotic curve along with assessment of the degree of skeletal maturity helps in the selection of curvature treatment (Burton, 2013). Multidisciplinary treatment is conducted by means of kinesitherapy, hydrokinesitherapy, occupational therapy, electrotherapy, spinal orthoses, but also of surgical treatment with partial correction and fusion of the primary curve.

Given that kinesitherapy, physical education and sport use the same means - motion, it is understandable that physical education teachers and sports trainers deal with this issue. Physical activity and therapeutic exercises have implications not only on development of morphological forms, but also on development of an organism as a whole. Well-organised physical activity at school age may reduce the number of persons with postural disorders and deformities.

The aim of kinesitherapy is improvement of muscle elasticity, reduction of pathological curves of the spinal column, muscle force increase, improvement of general fitness, and development of a balanced muscular corset for maintaining good posture. Motion and exercise in kinesitherapy are specific and they differ from gymnastics in physical education classes. What makes them specific is selection, initial position, character of exercises and dosing. Kinesitherapeutic programme will produce results within a certain period of time, but in time, by repeating the same exercises, due to monotony, children may lose motivation for the exercises. For that reason, after some time, elements of play or sports may be applied along with the therapeutic motion, with the aim of entertainment, but also of the effect on the spinal column. Selection of these elements depends on the postural disorder, deformity and degree of curvature.

\section{Role of physical activity in the devel- opment of musculoskeletal system}

Physical activity is very important and desirable in the development of children and their musculoskeletal system, but it requires certain efforts and is not harmless, so upon the doctor's recommendation, it may be discontinued or limited in the event of specific health condition and particular diseases.

We have conducted a research on physical activity of school-age children, presence of back pain and feeling of general good health, as well as of presence of differences between boys and girls in terms of the level of physical activity, on a sample of 98 schoolchildren of the average age of 11.4 years. The results of our research showed that the feeling of worse general health condition and back pain is more common in girls than in boys. An important predictor of the differences between boys and girls at the level of physical activity is the amount of time spent in play. Boys spend more time in outdoor play than girls (Jandric, 2010).

Games and sports may be very close to children, which facilitates their application to a great extent. Sport is recommended as one of the options in multidisciplinary treatment, but at the same time it is considered as a possible causal factor for occurrence of postural disorders, particularly scoliosis. For all those reasons, there are opposing opinions on the issue of scoliosis and sport.

For that reason, the goal of our work was to give an overview of available works on possible association between scoliosis and different sports, to present the results of the latest researches in this field, as well as the results of our own researches, aiming to evaluate and synthesise the existing results, as well as to give certain recommendations for participation of patients with scoliosis in particular sports activities.

\section{METHODS}

In our research, we performed a systematic review of literature, articulate articles and meta-analyses which give overviews of the latest findings about the aetiology and manifestation of postural disorders in children, implications of sport and physical activity on their development and health, as well as original articles and reports on the results of researches on possible association between various sports activities and scoliosis. For the research, we used PubMed, Cross References database, Google Scholar Citation index and other available literature. 


\section{ROLE OF SPORT IN THE GROWTH AND DEVELOPMENT OF A CHILD'S ORGANISM}

Growth and development of children depend on adequate stimulation, with motion as its most important factor. Motion is a basic biological need and it represents a stimulant of growth and development of the organism. It accelerates recovery of deteriorated functions, and produces favourable psychological and social effects as well (Radisavljević, 2001). Back in 1781, Tissot wrote that "motion by its effects substitutes for every therapeutic agent, while all therapeutic agents cannot substitute for motion". Sport, elements of sport, sports games and gymnastics represent one of quite successful methods for maintenance and improvement of health and mental balance, particularly in children and youth.

There are more and more reports on positive effects of kinesitherapy on scoliosis, thereby many people take a position that children with scoliosis up to 30 degrees may participate in specific sports. As a matter of fact, some sports are even recommended. Karski, Kalakucki, and Karski (2007) report on desirable effects of particular sports on the development of children's skeleton. In children with scoliosis, recommended are the sports which engage musculature symmetrically, such as gymnastics, rhythmic gymnastics and swimming, because they are considered to have favourable effects both on prevention and on the state of deformity. Symmetrical performance of exercises at practice uses exercises of mobility, balance, coordination, positional correction, exercises for strengthening trunk flexors and extensors. It is stated that participation in sports may also affect reduction of the lateral spinal curve in children with scoliosis (Mroczkowski \& Jaskólski, 2006).

\section{ASSOCIATION BETWEEN SPORTS AND SCOLIOSIS}

Young athletes may have spinal deformities which may be present per se and unrelated to any sports activity, or may be potentially associated with the sport they practise. (d'Hemecourt \& Hresko, 2012). Due to enormous one-sided loading lasting several years, sport may also have negative implications on the movement system. Potential association between AIS and sports is quite vague (Kenanidis, Potoupnis, $\mathrm{Pa}$ pavasiliou, Sayegh, \& Kapetanos, 2010). For all these reasons, there are opposing opinions on the issue of scoliosis and sport.
There are different reports in the literature on the implications of various sports on the prevalence of postural disorders in children. Researches have shown that the postural status is much better in high-class gymnasts and rhythmic gymnasts. The postural status of shooters is deteriorated, and in track and field athletes (high-class athletes competing in throwing disciplines) it is good. Several studies point out that certain sports show increased association with spinal deformities, particularly in adolescent girls (Green, Johnson, \& Moreau, 2009; Kenanidis, Potoupnis, Papavasiliou, Sayegh, \& Kapetanos, 2008). Nevertheless, patients with adolescent idiopathic scoliosis are still encouraged to engage in some sports activities (Wood, 2002). The highly repetitive nature of sport, amenorrhoea, excessive stress on the immature spine in professional athletes in adolescence and joint hypermobility may coexist during adolescence and be associated with increased incidence of AIS.

It is reported that it is necessary to avoid sports which engage musculature one-sidedly and asymmetrically, such as: rowing, fencing, tennis and track and field throwing disciplines (Pećina, 1982). Swärd (1992) reports that scoliosis is discovered in $80 \%$ of athletes with asymmetric loading of trunk and shoulders, such as javelin throwers and tennis players. On the basis of medicine founded on evidence, and in the scope of a systematic review of literature and other authoritative sources and reports, Green et al. (2009) suggested guidelines to health professionals and patients with scoliosis related to participation in physical and sports activities. They report on potential association between elite-level competition in specific sports at an early age and increased prevalence of scoliosis (grade $\mathrm{C}$ recommendation).

Rhythmic gymnastics as a sports discipline uses a series of specifically selected exercises which contribute to balanced and harmonic development of the organism as a whole. Symmetrical performance of exercises at practice, which is defined by strict requirements of equal use of both hands in the technique of manipulation of pieces of apparatus, creates a habit of proper body posture in all positions. On the other hand, Tanchev, Dzherov, Parushev, Dikov, and Todorov (2000) report that the incidence of scoliosis is ten times higher in persons who practise rhythmic gymnastics. In a research, Meyer et al. (2008) set the goal to determine the association between the IS type and the physical and sports activity in which they participate. The research included 169 adolescent girls with IS and 100 adolescent girls in the control group, comparable by years of age. They all completed an epidemiological questionnaire which contained infor- 
mation on their school and out-of-school physical and sports activities. The adolescents with a double major curve had more physical and sports activity than those with a single major curve. The most frequent activities in both groups were gymnastic activities. Among those who practised gymnastics, there was the greatest number of those with a double major curve. This could be associated with the fact that adolescents with a double major curve are less exposed to biomechanical forces related to scoliosis, which is a condition for better balance control, and those are essential factors in these physical and sports activities.

Damsgaard, Bencke, Matthiesen, Petersen, and Müller (2001) researched primarily anthropometric variables, body composition and development of puberty in children of 9-13 years of age, who participate in competitive sports. They also researched the implications of age, sport, practice (hours spent at practice) and development of puberty (time of experience of menarche) on the body composition and development of puberty. The research included 183 children who practised swimming, tennis, handball and gymnastics. The researchers came to the conclusion that there are anthropometric differences in the body composition in athletes of both genders in different sports, but they are more evident in girls. Most importantly, the authors report that they did not find any implications of practice on the body composition or puberty development, confirming the conclusions of previous reports which say that children in competitive sports are selected on the basis of constitutional factors.

Taking into consideration that the implications of physical and sports activities on IS are still vague, Meyer et al. (2006) conducted a research on the implications of sports activities on scoliosis. The results of the research showed that the patients with IS, regardless of whether they practised gymnastics or not, had a higher degree of joint hypermobility than the persons from the control group. The group who practised gymnastics did not show a higher degree of joint hypermobility than the other groups of interviewees. Children with increased joint hypermobility may decide on gymnastics due to the ability to adapt to the requirements of this sport. Girls with increased joint hypermobility are susceptible to IS. The fact that most of the adolescents with IS engage in gymnastics may be associated with increased joint hypermobility.

A recent research showed that 10 times higher incidence of scoliosis was found in persons practising rhythmic gymnastics $(12 \%)$ in comparison to the average population (1.1\%). Delayed menarche and generalised joint hypermobility are common in rhythmic gymnasts. The authors find that significant physical loading with persistently repeated asymmetric stress on the spinal column which is in the period of growth, is associated with the nature of rhythmic gymnastics. This study identified a special entity of scoliosis associated with rhythmic gymnastics. The results of the study clearly refer to importance of aetiological role of the "dangerous triad": generalised joint hypermobility, delayed maturity and asymmetric spinal loading (Tanchev et al., 2000).

Swimming. Beneficial effects of water, the buoyant force that facilitates movement, symmetric engagement of musculature, overcoming resistance, horizontal position, respiration, those are all benefits provided by swimming as a sport. It is of utmost importance to perform "corrective swimming". Classic breaststroke swimming has the greatest importance in hydrotherapy, because there are a number of modifications useful for treatment of spinal curves arising from it. Propulsion is ensured by symmetric movement of arms and legs. Swimming activates muscles of arms and shoulder girdle, trunk and legs. A recently conducted research aimed at evaluation of implications that regular swimming in school classes has on anthropometric variables and presence of postural deficit in children of 13.4 years of age. One group had, apart from regular classes, additional swimming classes once a week in the course of two years. The difference in body height and BMI between the groups was not significant. In the group with swimming, correction of scoliosis was more evident than in the control group. The authors conclude that along with standard swimming in schools, there should also be a special programme of corrective exercises in water, within the programme of physical education classes (Bielec, Peczak-Graczyk, \& Waade, 2013). Swimming is considered to be a complete sport and a treatment option for scoliosis, but recently published results of a research were contradictory to these opinions. The research conducted on a sample of 112 adolescents, who participated in competitive swimming and who were compared to 217 pupils of the same age (12.5 years), showed that swimming is associated with hyperkyphosis, with an increased risk of trunk asymmetry, as well as with increased prevalence of low back pain in females by 2.1 times (Zaina, Donzelli, Lusini, Minnella, \& Negrini, 2015).

Martial art techniques. Recent researches show that deformities of skeletal system could be associated with "syndrome of seven contractures", described by Mau (1982) as "Siebener Kontrakturen Syndrom". This syndrome was also described by Green and 
Griffin (1982). According to them, the asymmetry in hips and pelvis region is induced by abduction contracture of the left hip and/or the right hip (shortening of the muscles, tendons, fasciae). For children with the "syndrome of contractures" it is recommended to conduct early prophylaxis programme for scoliosis in accordance with the type of deformity. The abduction contracture of the right hip has significant implications on the spinal column in the period when a child starts standing and walking. It is stated that in sports activities the best exercises are stretching like "warm-up" in martial art techniques: kung fu, karate, taekwondo, tai chi, aikido, yoga, etc. in treatment of postural disorders and IS (Karski et al., 2007).

In our research conducted on a sample of 66 school-age children of the average age of 11.1 years, we assessed the presence of postural disorders and spinal deformities in a group of children composed of those who practise karate and those who do not. The results of our research showed that the children who practise karate have by $46.7 \%$ lower percentage of scoliotic posture and scoliosis, but they have a higher percentage of kyphotic posture and kyphosis $(33.3 \%)$ and lordosis $(10 \%)$ in comparison with the children who do not practise karate. This also indicates the importance of activation of particular muscle groups during practice (Jandrić, Janković, \& Vranić, 2009).

Dance and ballet. There are few reports in the literature on the association between scoliosis and the process of growth, between scoliosis and intensive exercises, between scoliosis and morphological characteristics, as well as between scoliosis and injuries in young dancers. A recent study, conducted on a sample of 1.288 non-professional dancers in the 8-16 age range, researched the experience, body structure, anatomical anomalies and injuries which could be associated with scoliosis, and identified the variables that can be used to determine the difference between the dancers with scoliosis and without scoliosis at the time of the screening. Scoliosis was diagnosed in $23.8 \%$ of the dancers. The dancing experience and body structure were similar in the dancers with and without scoliosis. The dancers with scoliosis had significantly higher presence of genu varum and hallux valgus. Back pain caused by injuries was more common in the dancers with scoliosis in comparison with the dancers who did not have scoliosis (Steinberg et al., 2013).

In order to determine the difference in prevalence of AIS in 30 ballerinas in the 9-16 age range, the girls were compared to their peers who are not ballerinas.
The research addressed the association between the presence of scoliosis and generalised joint hypermobility, menarche, BMI and the number of hours of practice per week. Scoliosis was diagnosed in 30\% of the ballerinas in comparison with $3 \%$ of those in the control group. The results showed that ballerinas have 12.4 times higher probability of occurrence of scoliosis than girls of the same age who do not practice ballet. In the group of ballerinas, a higher degree of hypermobility was present $(70 \%)$ in comparison with those who do not practice dancing (3\%), but no statistically significant association was found between scoliosis and hypermobility, menarche, BMI or the number of hours of dancing per week. Considering a higher risk of occurrence of scoliosis, the authors emphasise the need for vigilant screening and improvement of education of dance teachers and parents, which may be of great benefit in early detection and reduction of risk of possible surgical intervention (Longworth, Fary, \& Hopper, 2014).

Yoga and Pilates. Elements of these exercises may be incorporated in various therapy programmes for treatment of spinal deformities.

A radiological study of thoracolumbar spine was conducted on a sample of 143 athletes (wrestlers, gymnasts, footballers and tennis players) in the 14-25 age range and 30 males in the 19-25 age range who do not practice any sports. There are various types of radiological abnormalities both in the athletes and in those who do not practice any sports, but they were more common in the athletes, particularly in the male gymnasts and wrestlers. Abnormalities of vertebral ring apophysis occur exclusively in athletes. A combination of various types of abnormalities was most common in male gymnasts and wrestlers (Hellström, Jacobsson, Swärd, \& Peterson, 1990).

Parsch, Gärtner, Brocai, Carstens, and Schmitt (2002) report that, in the long term, the patients with IS have functional impairments in comparison with their peers in the control group, and the main cause is functional deficit and frequency of low back pain syndrome.

Fusco et al. (2011) do not advise participation in competitive sports which require increased spinal range of motion, particularly in maximum thoracic spine extension and/or lumbar spine flexion, but they recommend to patients with scoliosis every type of sports activity at the recreational level. Such activities of limited intensity and duration cannot cause structural changes, but they provide significant benefit in the physical and psychological aspect.

In order to identify recommendations related to return to sports and athletic activities after surgical 
treatment of AIS, a research was conducted at the level of the Spinal Deformity Study Group members. The research was completed by twenty-three surgeons. It was concluded that modern posterior instrumentation allows surgeons to recommend early return to sports activities after fusion for AIS. Most of them allow running 3 months after, non-contact sports and contact sports 6 months after, and collision sports 12 months after surgical treatment of scoliosis (Lehman, Kang, Lenke, Sucato, \& Bevevino, 2013).

The International Scientific Society on Scoliosis Orthopaedic and Rehabilitation Treatment [SOSORT] guidelines for sports activities of children with scoliosis. This association does not recommend sport for treatment of idiopathic scoliosis. Within the guidelines, sports activities are recommended due to their specific useful effects in the psychological, neuromuscular and general aspect of health in patients with scoliosis, even in patients during the treatment with spinal orthoses, with the aim of increasing aerobic capacity and producing psychological effects. They are recommended in the course of all phases of treatment, within the classes of physical education. Limits for specific types of sports activities are determined by a medical specialist, taking into consideration the degree of deformity and other circumstances. During the treatment with spinal orthoses, SOSORT recommends caution in contact and highly dynamic sports activities. It also recommends for patients with a high risk of scoliosis progression to avoid competitive activities with a higher degree of mobility of the spinal column (Negrini, Aulisa, \& Zaina, 2012; Jandric, 2012b).

\section{CONCLUSION}

In young people, exercises and athletic competitions are socially important. Sport is not recommended for treatment of idiopathic scoliosis, but sports activities are recommended for their specific useful effects in the psychological, neuromuscular and general aspect of health. Young athletes may have scoliosis which can be present per se and unrelated to any sports activity, or it may be potentially associated with the sport they practise. Due to enormous one-sided loading lasting several years, sport may also have negative implications on the movement system, but potential association between AIS and sports is still insufficiently researched, and requires further studies. Athletic activities and participation in sports are usually allowed to patients with scoliosis who use conservative methods of treatment, but caution is recommended in contact and highly dy- namic sports activities. Return to sport after surgical treatment is variable, and it is based on a decision of the operating surgeon on the basis of the degree of fusion and the sports activity.

\section{REFERENCES}

Bielec, G., Peczak-Graczyk, A., \& Waade, B. (2013). Do swimming exercises induce anthropometric changes in adolescents? Issues Compr Pediatr Nurs, 36(1-2), 37-47. doi: 10.3109/01460862.2013. 777818; PMid: 23597276

Burton, M. S. (2013). Diagnosis and treatment of adolescent idiopathic scoliosis. Pediatr Ann, 42(11), 224-228. doi: 10.3928/0090448120131022-09; PMid: 24168116

Damsgaard, R., Bencke, J., Matthiesen, G., Petersen, J. H., \& Müller, J. (2001). Body proportions, body composition and pubertal development of children in competitive sports. Scand J Med Sci Sports, 11(1), 54-60. doi: 10.1034/j.1600-0838. 2001.011001054.x; PMid: 11169236

d'Hemecourt, P. A., \& Hresko, M. T. (2012). Spinal deformity in young athletes. Clin Sports Med, 31(3), 441-451. doi: 10.1016/j.csm.2012.03.013; PMid: 22657994

Fusco, C., Zaina, F., Atanasio, S., Romano, M., Negrini, A., \& Negrini, S. (2011). Physical exercises in the treatment of adolescent idiopathic scoliosis: An updated systematic review. Physiotherapy Theory and Practice, 27(1), 80-114. doi: 10.3109/09593985.2010.533342; PMid: 21198407

Górecki, A., Kiwerski, J., Kowalski, I. M., Marczyński, W., Nowotny, J., Rybicka, M. ... Szlachowska-Kluza, W. (2009). Bad posture prevention in children and youth in education and upbringing- experts recommendations. Pol Ann Med, 16(1), 168-177.

Green, N. E., \& Griffin, P. P. (1982). Hip dysplasia associated with abduction contracture of the contralateral hip. JBJS, 63-A, 1273-1281.

Green, B. N., Johnson, C., \& Moreau, W. (2009). Is physical activity contraindicated for individuals with scoliosis? A systematic literature review. $J$ Chiropr Med, 8(1), 25-37. doi: 10.1016/j.jcm. 2008.11.001, PMid: 19646383; PMCid:PMC 2697577

Hellström, M., Jacobsson, B., Swärd, L., \& Peterson, L. (1990). Radiologic abnormalities of the thoraco-lumbar spine in athletes. Acta Radiol, 1(2), 127-132. doi: 10.1177/028418519003 100202; doi: 10.3109/02841859009177473 
Jandrić, S. (2010). Differences between boys and girls in terms of physical activity. Facta Universitatis, 8(1), 1-7.

Jandric, S. (2012a). Idiopatske skolioze [Idiopathic scoliosis]. Med Pregl, 65(1-2), 35-40. doi: 10.2298/MPNS1202035J; PMid: 22452237

Jandric, S. (2012b). Skolioze, kifoze i lordoze [Scoliosis, kyphosis and lordosis]. Laktaši, Bosnia and Herzegovina: Grafomark.

Jandrić, S, \& Antić, B. (2006). Low back pain and degenerative disc disease. Med Pregl., 59(9-10), 456-461. doi: 10.2298/MPNS0610456J

Jandrić, S., Janković, Z., \& Vranić, J. (2009). Efekat karate treninga na pojavu posturalnih poremećaja i deformiteta kod djece školskog uzrasta [The effect of karate training on the incidence of postural disorders and deformities in children of school age]. In G. Bošnjak (Ed.), Prvi međunarodni naucni kongres, Antropološki aspek.ti sporta, fizičkog vaspitanja i rekreacije" (pp. 275-279). Banjaluka, Bosna and Herzegovina: Fakultet fizičkog vaspitanja i sporta Univerziteta Banja Luka.

Jovović, V. (2008). Korektivna gimnastika sa kineziterapijom [Corrective gymnastics with kinesitherapy]. 2nd ed. Nikšić, Montenegro: Filozofski fakultet, Nikšić.

Karski, T., Kalakucki, J., \& Karski, J. (2007). Relationship of "syndrome of contractures" in newborns with the development of the socalled idiopathic scoliosis. World J Pediatr, 3(4), 254-259.

Kenanidis, E. I., Potoupnis, M. E., Papavasiliou, K. A., Sayegh, F. E., \& Kapetanos, G. A. (2008). AIS and exercising: is there truly a liaison? Spine, 33(20), 2160-2165. doi: 10.1097/

BRS.0b013e31817d6db3; PMid: 18794756

Kenanidis, E. I., Potoupnis, M. E., Papavasiliou, K. A., Sayegh, F. E., \& Kapetanos, G. A. (2010). Adolescent idiopathic scoliosis in athletes: is there a connection? Phys Sportsmed, 38(2), 165170. doi: 10.3810/psm.2010.06.1795; PMid: 20631476

Kratenová, J., Zejglicová, K., Malý, M., \& Filipová V. (2007). Prevalence and risk factors of poor posture in school children in the Czech Republic. J Sch Health, 77(3), 131-137. doi: 10.1111/j.1746-1561.2007.00182.x; PMid: 17302855

Łabaziewicz, L. (2008). Faulty postures. In W. Marciniak and A. Szulc (Eds.), Orthopaedics and Rehabilitation of Wiktor Dega (Vol. 2; pp. 63-77). Warsaw, Poland: PZWL.
Lehman, R. A. Jr., Kang, D. G., Lenke, L. G., Sucato, D. J., \& Bevevino, A. J. (2015). Spinal Deformity Study Group. Return to sports after surgery to correct adolescent idiopathic scoliosis:a survey of the Spinal Deformity Study Group. Spine J, 15(5), 951-958. doi: 10.1016/j. spinee.2013.06.035; PMid: 24099682

Longworth, B., Fary, R., \& Hopper, D. (2014). Prevalence and predictors of adolescent idiopathic scoliosis in adolescent ballet dancers. Arch Phys Med Rehabil, 95(9), 1725-1730. doi: 10.1016/j.apmr.2014.02.027; PMid: 24662812

Mau, H. (1982). Atiopatogenese der Skoliose [Etiopathogenesis of scoliosis]. In Bücherei des Orthopäden (pp. 1-110). Stuttgart, Germany: Enke Verlag.

Meyer, C., Cammarata, E., Haumont, T., Deviterne, D., Gauchard, G. C., \& Leheup, B. (2006). Why do idiopathic scoliosis patients participate more in gymnastics? Scand J Med Sci Sports, 16(4), 231236. doi: 10.1111/j.1600-0838.2005.00482.x; PMid: 16895527

Meyer, C., Haumont, T., Gauchard, G. C., Leheup, B., Lascombes, P., \& Perrin, P. (2008). The practice of physical and sporting activity in teenagers with idiopathic scoliosis is related to the curve type. Scand J Med Sci Sports, 18(6), 751755. 10.1111/j.1600-0838.2007.00750.x; PMid: 18248544

Mroczkowski, A., \& Jaskólski, E. (2006). Effects of aikido exercises on lateral spine curvatures in children. Archives of Budo, 2(4), 31-34

Negrini, S., Aulisa, A. G., \& Zaina, F. (2012). 2011

SOSORT guidelines: Orthopaedic and Rehabilitation treatment of idiopathic scoliosis during growth. Scoliosis, 7(1), 3. doi: 10.1186/1748-7161-7-3; PMid: 22264320; PMCid: PMC3292965

Parsch, D., Gärtner, V., Brocai, D. R., Carstens, C., \& Schmitt, H. (2002). Sports activity of patients with idiopathic scoliosis at long-term follow-up. Clin I Sport Med, 12(2), 95-98. doi: 10.1097/00042752-200203000-00005; PMid: 11953555

Pećina, M. (1982). Nauka o mišićima [Science of muscle]. In N. J.. Krmpotić (Ed.), Anatomija covjek. (pp. 235-252). Zagreb, Croatia: Jumena.

Radisavljević, M. (2001). Korektivna gimnastika sa osnovama kineziterapije [Corrective gymnastics with the basics of kinesitherapy]. Belgrade, Serbia: Viša škola za sportske trenere, Beograd.

Rogala, E. J., Drummond, D. S., \& Gurr, J. (1978). Scoliosis: incidence and natural history. A 
prospective epidemiological study. J Bone Joint Surg Am, 60(2), 173-176.

Sedrez, J. A., Da Rosa, M. I., Noll, M., Medeiros, F. D., \& Candotti, C. T. (2015). Risk factors associated with structural postural alterations on the spine of children and adolescents. Revista Paulista de Pediatria, 33(1), 72-81. doi: 10.1016/j. rpped.2014.11.012; PMid: 25623725; PMCid: PMC4436959

Steinberg, N., Hershkovitz, I., Peleg, S., Dar, G., Masharawi, Y., Zeev, A., \& Siev-Ner, I. (2013). Morphological characteristics of the young scoliotic dancer. Phys Ther Sport, 14(4), 213-220. doi: 10.1016/j.ptsp.2012.07.003; PMid: 23146194

Stirling, A. J, Howel, D., Millner, P. A., Sadiq, S., Sharples, D., \& Dickson, R. A. (1996). Lateonset idiopathic scoliosis in children six to fourteen years old: A cross-sectional prevalence study. J Bone Joint Surg Am, 78(9), 1330-1336.

Swärd, L. (1992). The thoracolumbar spine in young elite athletes. Current concepts on the effects of physical training. Sports Med, 13(5), 357-364. doi: 10.2165/00007256-19921305000005

Taft, E., \& Francis, R. (2003). Evaluation and Management of Scoliosis. J Pediatr Health Care, 17(1), 42-44. doi: 10.1016/S08915245(02)88307-9; doi: 10.1067/mph.2003.7; PMid: 12533733

Tanchev, P. I., Dzherov, A. D., Parushev, A. D., Dikov, D. M., \& Todorov, M. B. (2000). Scoliosis in rhythmic gymnasts. Spine, 25(11), 1367-1372. doi: 10.1097/00007632-200006010-00008; PMid: 10828918

Wood, K. B. (2002). Spinal deformity in the adolescent athlete. Clin Sports Med, 21(1), 77-92. doi: 10.1016/S0278-5919(03)00058-9

Zaina, F., Donzelli, S., Lusini, M., Minnella, S., \& Negrini, S. (2015). Swimming and spinal deformities: a cross-sectional study. J Pediatr, 166(1), 163-167. doi: 10.1016/j. jpeds.2014.09.024; PMid: 25444007

Received: Febreuary 5, 2015

Revision received: May 15, 2015

Accepted: May 15, 2015

Correspondence to: Slavica Jandrić, PhD School of Medicine Save Mrkalja 14

78000 Banja Luka

Bosnia and Herzegovina Phone: 0038765618092

Fax: 0038751234101

E-mail: slavajandric@yahoo.com 